\title{
In Vivo Imaging of the Glucagonlike Peptide 1 Receptor in the Pancreas with ${ }^{68}$ Ga-Labeled DO3A-Exendin-4
}

\author{
Ram K. Selvaraju ${ }^{1}$, Irina Velikyann ${ }^{1,2}$, Lars Johansson ${ }^{3,4}$, Zhanhong Wu ${ }^{5}$, Ivan Todorov ${ }^{5}$, Jack Shively ${ }^{5}$, Fouad Kandeel ${ }^{5}$, \\ Olle Korsgren $^{6}$, and Olof Eriksson ${ }^{1}$ \\ ${ }^{1}$ Preclinical PET Platform, Department of Medicinal Chemistry, Uppsala University, Uppsala, Sweden; ${ }^{2}$ PET Centre, Centre for \\ Medical Imaging, Uppsala University Hospital, Uppsala, Sweden; ${ }^{3}$ Department of Radiology, Oncology, and Radiation Sciences, \\ Uppsala University, Uppsala, Sweden; ${ }^{4}$ AstraZeneca $R \& D$, Mölndal, Sweden; ${ }^{5}$ Beckman Research Institute of the City of Hope, \\ Duarte, California; and ${ }^{6}$ Department of Immunology, Genetics, and Pathology, Uppsala University, Uppsala, Sweden
}

The glucagonlike peptide 1 receptor (GLP-1R) is mainly expressed on $\beta$-cells in the islets of Langerhans and is therefore an attractive target for imaging of the $\beta$-cell mass. In the present study, ${ }^{68} \mathrm{Ga}$-labeled exendin-4 was evaluated for PET imaging and quantification of GLP-1R in the pancreas. Methods: Dose escalation studies of ${ }^{68} \mathrm{Ga}$-labeled 1,4,7-tris(carboxymethylaza)cyclododecane-10-azaacetyl (DO3A)-exendin-4 were performed in rats (organ distribution) and cynomolgus monkeys (PET/CT imaging) to determine the GLP-1R-specific tissue uptake in vivo. Pancreatic uptake (as determined by organ distribution) in healthy rats was compared with that in diabetic rats. GLP-1R occupancy in the cynomolgus pancreas was quantified with a 1-tissue-compartment model. Results: In rodents, uptake in the pancreas was decreased from the baseline by up to $90 \%(P<0.0001)$ by coadministration of DO3A-exendin-4 at $100 \mu \mathrm{g} / \mathrm{kg}$. Pancreatic uptake in diabetic animals was decreased by more than $80 \%(P<0.001)$ compared with that in healthy controls, as measured by organ distribution. GLP-1R occupancy in the cynomolgus pancreas after coinjection of DO3Aexendin-4 at $0.15-20 \mu \mathrm{g} / \mathrm{kg}$ ranged from $49 \%$ to $97 \%$, as estimated by compartment modeling. Conclusion: These results strongly support the notion that ${ }^{68} \mathrm{Ga}-\mathrm{DO} 3 \mathrm{~A}-\mathrm{exendin}-4$ uptake in the pancreas is mediated by specific receptor binding. In addition, pancreatic uptake was decreased by selective destruction of $\beta$-cells. This result suggests that GLP-1R can be quantified in vivo, which has major implications for the prospect of imaging of native $\beta$-cells.

Key Words: $\beta$-cell imaging; $\beta$-cell mass; GLP-1R

J Nucl Med 2013; 54:1458-1463

DOI: 10.2967/jnumed.112.114066

\section{D} iabetes is one of the most common chronic diseases, and so far no cure is available for either type 1 diabetes or type 2 diabetes. Noninvasive quantification of the $\beta$-cell mass would allow assessment of the effects of new treatments aimed at $\beta$-cell regeneration, prevention of autoimmune $\beta$-cell destruction, and engraftment and survival of transplanted islets. Such quantification

\footnotetext{
Received Sep. 14, 2012; revision accepted Feb. 24, 2013.

For correspondence or reprints contact: Olof Eriksson, Preclinical PET Platform (PPP), Department of Medicinal Chemistry, Uppsala University, Dag Hammarskjölds Väg 14C, 3tr, SE-751 83 Uppsala, Sweden.

E-mail: olof.eriksson@pet.medchem.uu.se

Published online Jun. 12, 2013.

COPYRIGHT (c) 2013 by the Society of Nuclear Medicine and Molecular Imaging, Inc.
}

would also allow analysis of more basic biologic properties, such as the etiology and disease progression of both type 1 diabetes and type 2 diabetes $(1,2)$.

The glucagonlike peptide 1 (GLP-1) receptor (GLP-1R) is predominantly localized to $\beta$-cells in the islets of Langerhans and is absent or limited in the exocrine parenchyma and pancreatic ductal cells $(3,4)$. Because native GLP-1 is degraded rapidly by dipeptidyl peptidase IV, a more stable agonist of GLP-1 (such as exendin-4) is a preferred imaging agent. Previously, exendin- 4 was radiolabeled with long-lived nuclides, such as ${ }^{111} \mathrm{In}(5,6)$ and ${ }^{64} \mathrm{Cu}(7,8)$, for use in SPECT and PET. These analogs have shown promise for imaging of tumors of $\beta$-cell origin (insulinomas) as well as transplanted islets (9). However, the substantial residence time and, thus, the localized radiation dose of these radionuclides, especially in the kidney cortex, limit their use in clinical settings.

Imaging with PET nuclides yields better resolution than imaging with SPECT nuclides, such as ${ }^{111} \mathrm{In}$. In addition, PET can be quantified in absolute terms - a prerequisite for quantifying (as opposed to simply visualizing) - $\beta$-cell mass in the pancreas or in the islet graft. 1,4,7-tris(carboxymethylaza)cyclododecane-10azaacetyl (DO3A)-exendin-4 was previously shown to have a $50 \%$ inhibitory concentration comparable to that of nonmodified exendin-4 (7) and contains a DO3A chelator that is suitable for labeling with the positron-emitting nuclide ${ }^{68} \mathrm{Ga}(10)$.

In the present study, DO3A-exendin- 4 was labeled with the PET nuclide ${ }^{68} \mathrm{Ga}$ and evaluated in rodents and nonhuman primates by dose escalation to investigate the potential for the in vivo quantification of GLP-1R in the pancreas.

\section{MATERIALS AND METHODS}

\section{Radiochemistry}

Materials. The purchased chemicals were used without further purification: sodium acetate buffer ( $\mathrm{pH} 4.6 ; 31048$; Sigma-Aldrich), $30 \% \mathrm{HCl}$ (ultrapure; 1.00318.0250; Merck), and trifluoroacetic acid (Merck). Deionized water (18.2 M $\Omega$ ) produced with a Maxima Elga System (Purelab) was used in all reactions. DO3A-VS-Cys40-exendin4 (GMP grade; C S Bio Co.) (VS is vinyl sulfone) was dissolved in deionized water to yield $1 \mathrm{mM}$ stock solutions.

Synthesis of ${ }^{68} \mathrm{Ga}-\mathrm{DO} 3 \mathrm{~A}-\mathrm{VS}$-Cys40-Exendin-4. ${ }^{68} \mathrm{Ga}$ (half-life, $68 \mathrm{~min}$ ) was available from two ${ }^{68} \mathrm{Ge} /{ }^{68} \mathrm{Ga}$ generator systems in which ${ }^{68} \mathrm{Ge}$ was attached to a column of an inorganic matrix based on titanium dioxide (1,850 MBq; Eckert \& Ziegler Eurotope $\mathrm{GmbH})$ and tin dioxide $(1,850 \mathrm{MBq}$; IDB Holland $\mathrm{BV})$. When the former generator was used, the first fraction of $1.5 \mathrm{~mL}$ was discarded and the next 1.5 $\mathrm{mL}$, containing over $90 \%$ of the total radioactivity, was collected and 
buffered with $200 \mu \mathrm{L}$ of acetate buffer and $15 \mu \mathrm{L}$ of sodium hydroxide to provide a $\mathrm{pH}$ of $4.6 \pm 0.4$ (mean $\pm \mathrm{SD}$ ). When the latter generator was used, the first fraction of $1.0 \mathrm{~mL}$ was discarded and the next 1.5 $\mathrm{mL}$, containing over $90 \%$ of the total radioactivity, was collected and buffered with $200 \mu \mathrm{L}$ of acetate buffer and $60 \mu \mathrm{L}$ of sodium hydroxide to provide a $\mathrm{pH}$ of $4.6 \pm 0.4$. Then, $10 \mathrm{nmol}$ of DO3A-VS-Cys40exendin- 4 was added, and the reaction mixture was incubated at $80^{\circ} \mathrm{C}-$ $85^{\circ} \mathrm{C}$ for $15 \mathrm{~min}$. The resulting product, ${ }^{68} \mathrm{Ga}$-DO3A-VS-Cys 40 -exendin- 4 ( ${ }^{68} \mathrm{Ga}$-DO3A-exendin-4), was formulated in phosphate-buffered saline, and its stability was monitored for $4 \mathrm{~h}$. The formulated product ( $\mathrm{pH} 7.4$ ) was filtered in a sterile manner.

Quality Control. Quality control was performed by high-performance liquid chromatography with a LaChrom Elite system (VWRHitachi) consisting of an L-2130 pump (Hitachi), an L-2400 UV detector (Hitachi), and a radiation flow detector (Bioscan) coupled in series. Separation of the analytes was accomplished by use of an endcapped analytic column with a stationary phase of covalently bonded pentylsilane (Discovery BIO Wide Pore C5; $5 \mathrm{~cm} \times 4.6 \mathrm{~mm}$; SigmaAldrich). The conditions were as follows: solvent A consisted of 10 $\mathrm{mM}$ trifluoroacetic acid; solvent B consisted of $70 \%$ acetonitrile, $30 \%$ $\mathrm{H}_{2} \mathrm{O}$, and $10 \mathrm{mM}$ trifluoroacetic acid with $\mathrm{UV}$ detection at $220 \mathrm{~nm}$; gradient elution was done for 0-2 $\mathrm{min}$ at $35 \% \mathrm{~B}, 2-9 \mathrm{~min}$ at $35 \%-$ $100 \% \mathrm{~B}$, and $9-12 \mathrm{~min}$ at $100 \%$ solvent $\mathrm{B}$; and the flow rate was 2.0 $\mathrm{mL} / \mathrm{min}$. Data acquisition and processing were performed with an EZChrom Elite Software Package (Agilent Technologies).

The recovery of radioactivity from the high-performance liquid chromatography was determined by performing analyses with and without the column. Fractions were collected for subsequent measurement of the radioactivity in a well-type $\mathrm{NaI}(\mathrm{Tl})$ scintillation counter. Measurements were corrected for dead time and for decay.

\section{Small-Animal Studies}

Lewis rats $(n=46 ; 355.5 \pm 13.1 \mathrm{~g})$ were housed under standard laboratory conditions and had free access to food and water. All handling procedures and experiments were performed in accordance with the guidelines of Uppsala University and were approved by the local ethics committee for animal research.

Distribution in Rodent Organs. Lewis rats $(n=42)$ were used in the biodistribution studies. Seven of the rats were treated with streptozotocin at $55 \mathrm{mg} / \mathrm{kg}$ to induce diabetes and $\beta$-cell destruction. A Bayer COUNTER monitoring unit (Bayer AG) was used to measure glucose in blood from the tail vein, and diabetes was defined as sequential measurements of greater than $20 \mathrm{mM}$ glucose. The rodents were anesthetized with $3.5 \%$ isoflurane in $50 \% / 50 \%$ medical oxygen:air at $450 \mathrm{~mL} / \mathrm{min}$, and then $0.8-10 \mathrm{MBq}$ of ${ }^{68} \mathrm{Ga}-\mathrm{DO} 3 \mathrm{~A}-$-exendin- 4 were coinjected with escalating doses of unlabeled DO3A-exendin-4 peptide $(0.1,1,2$, and $100 \mu \mathrm{g} / \mathrm{kg})$. The increasing amounts of unlabeled DO3A-exendin-4 should progressively compete with the radiolabeled ligand for binding to GLP-1R to indicate the receptor-specific tissue uptake in vivo. The animals were allowed to wake up immediately after tracer administration and were sacrificed (with $\mathrm{CO}_{2}$ ) 30, 60, or $80 \mathrm{~min}$ later. The pancreas was resected and weighed, the radioactivity was measured in a well counter, and the uptake was related to the concentration of tracer in the blood as the pancreas-to-blood uptake ratio.

Small-Animal PET/CT Imaging of Rodents. Lewis rats $(n=4)$ were sedated with isoflurane (controlled with an anesthesia vaporizer, initially at $3.2 \%$ and then at $3.0 \%$ to maintain anesthesia) blended with air: $\mathrm{O}_{2}$ at $450 \mathrm{~mL} / \mathrm{min}$ and delivered through a face mask. A catheter was placed in the tail vein. The animal was placed on the heated bed of a Triumph Trimodality System (Gamma Medica Inc.) to prevent hypothermia. Breathing rate and body temperature were monitored with an integrated physiologic monitoring system. ${ }^{68} \mathrm{Ga}$-DO3A-exendin- 4 at a dose of $18.5 \pm 4.7 \mathrm{MBq} / \mathrm{kg}$ in a maximum volume of 500 $\mu \mathrm{L}$ was administered as a single bolus injection via the tail vein catheter, and the animal underwent small-animal PET examination of the abdomen for $60 \mathrm{~min}$ in the list mode. The datasets were reconstructed into 8 time frames $(4 \times 5 \mathrm{~min}$ and $4 \times 10 \mathrm{~min})$ with a maximum-likelihood expectation maximization 3-dimensional algorithm (10 iterations). Small-animal PET data were analyzed with PMOD version 3.13 (PMOD Technologies Ltd.). Volumes of interest were drawn manually to include the pancreas, liver, and other tissues of interest in early or summed frames, and the uptake was expressed as the standardized uptake value (SUV).

\section{GLP-1R Imaging of Nonhuman Primates}

PET/CT Scanning. The nonhuman primate experiments were performed in accordance with the guidelines of Uppsala University and were approved by the local ethics committee for animal research. Cynomolgus monkeys ( $n=3 ; 5.6,7.4$, and $9.0 \mathrm{~kg})$ were sedated with intravenous ketamine $(10 \mathrm{mg} / \mathrm{kg})$ and propofol before being intubated and connected to a respirator. After intubation, the animals were maintained on $1.4 \%-4 \%$ sevoflurane inhalation anesthesia and artificial ventilation. Body temperature, heart rate, electrocardiogram, $\mathrm{pCO}_{2}, \mathrm{pO}_{2}$, $\mathrm{SaO}_{2}$, and blood pressure were monitored throughout the study. Two venous catheters were applied, one for tracer administration and one for sampling of blood radioactivity concentration.

The animal was positioned to include the abdomen in the $15-\mathrm{cm}$ axial field of view of a Discovery ST PET/CT scanner (GE Healthcare) with the assistance of a low-dose CT scout view (140 kV, $10 \mathrm{mAs})$. Attenuation correction was acquired with a CT examination at $140 \mathrm{kV}$ and $10-80 \mathrm{~mA} .{ }^{68} \mathrm{Ga}-\mathrm{DO} 3 \mathrm{~A}-$-exendin-4 $(0.2-2 \mathrm{MBq} / \mathrm{kg})$ was coadministered with escalating doses of unlabeled DO3A-exendin- 4 peptide $(0.05-20 \mu \mathrm{g} / \mathrm{kg})$. The $50 \%$ effective dose $\left(\mathrm{ED}_{50}\right)$ for exendin-4 in diabetic rhesus monkeys was previously shown to be on the order of $0.25 \mu \mathrm{g} / \mathrm{kg}(11)$. We therefore expected to find a decrease in the pancreatic uptake of ${ }^{68} \mathrm{Ga}$-DO3A-exendin- 4 at peptide doses above this dose because of competition for remaining GLP-1R.

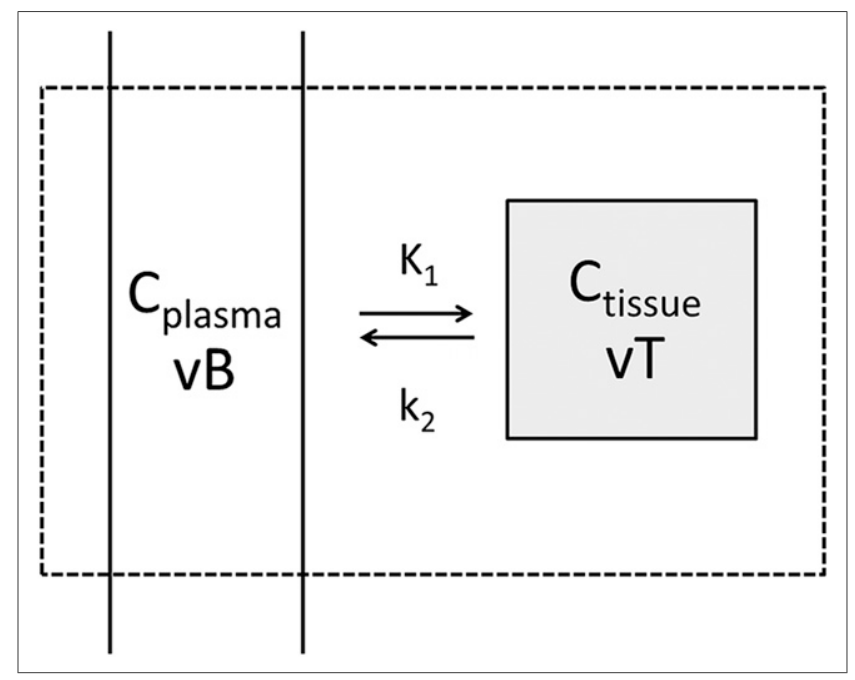

FIGURE 1. 1TC model. Three parameters (vB, $K_{1}$, and $\left.k_{2}\right)$ determine fit between model and experimental data, where $K_{1}$ and $k_{2}$ are rate constants determining extraction and washout of tracer, respectively. In this setting, $K_{1}$ can be interpreted as rate of tracer internalization intracellularly by interaction with GLP-1R, and $k_{2}$ represents washout of unbound tracer from tissue. Compound parameter vT (which is equal to ratio of $K_{1}$ to $k_{2}$ ) is therefore expected to decrease because of competition for GLP-1R with unlabeled ligand in excess. $\mathrm{C}_{\text {plasma }}=$ concentration in plasma; $\mathrm{C}_{\text {tissue }}=$ concentration in tissue. 


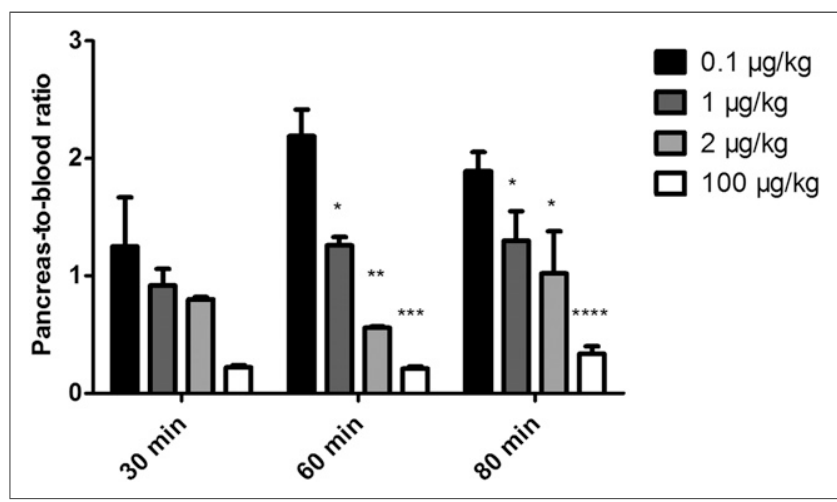

FIGURE 2. Pancreas-to-blood uptake ratio of ${ }^{68} \mathrm{Ga}-\mathrm{DO} 3 \mathrm{~A}-\mathrm{exen}-$ din-4 in rats, as measured by ex vivo organ distribution. Uptake of ${ }^{68} \mathrm{Ga}-\mathrm{DO} 3 \mathrm{~A}-\mathrm{exendin}-4$ in pancreas was progressively decreased by coadministration of increasing amounts of unlabeled DO3A-exendin-4. Maximum uptake in pancreas was found at administered mass peptide dose of $0.1 \mu \mathrm{g} / \mathrm{kg}$, which was below estimated $E_{50}$ (11). Uptake was progressively decreased at all time points by administration of peptide doses exceeding $\mathrm{ED}_{50}(1$ and $2 \mu \mathrm{g} / \mathrm{kg})$. Only minor levels of tracer uptake (10\%-20\%) remained when complete GLP-1R inhibition was induced by administration of DO3Aexendin-4 at $100 \mu \mathrm{g} / \mathrm{kg}$. Asterisks indicate significance compared with baseline dose $(0.1 \mu \mathrm{g} / \mathrm{kg})$, as assessed by 1 -way ANOVA. ${ }^{*} P<$ 0.05. ${ }^{\star \star} P<0.01$. ${ }^{\star \star *} P<0.001$. ${ }^{\star \star \star *} P<0.0001$.

${ }^{68} \mathrm{Ga}$-DO3A-exendin-4 and unlabeled DO3A-exendin-4 were administered intravenously, and the animals were examined with a dynamic PET protocol for $90 \min (33$ frames; $12 \times 10 \mathrm{~s}, 6 \times 30 \mathrm{~s}, 5 \times 120 \mathrm{~s}, 5 \times$ $300 \mathrm{~s}$, and $5 \times 600 \mathrm{~s}$ ). Directly after the abdominal dynamic scan, the animals were examined with a multibed scan ( 3 or 4 partly overlapping bed positions) to cover the entire body. PET data were acquired for $5 \mathrm{~min}$ in each bed position. Attenuation correction and morphologic CT were accomplished in the same manner as for the dynamic scan.

Venous blood samples $(0.2-0.5 \mathrm{~mL})$ were collected at $0.5,1,3,5,10$, $15,20,30,45,60$, and $90 \mathrm{~min}$ after each injection to measure the radioactivity concentrations in whole blood and plasma.

Image acquisition was performed in a 3-dimensional format and reconstructed with an iterative ordered-subset expectation maximization VUEPOINT (GE Healthcare) algorithm (2 iterations and 21 subsets; $128 \times 128$ matrix). Reconstructed data were analyzed with PMOD. Regions of interest were drawn on coregistered CT images or on early or summed PET images. Entire organs were measured as volumes of interest when possible. Uptake was expressed as the SUV, which relates the tissue radiotracer concentration (in $\mathrm{Bq} / \mathrm{mL}$ ) to the total amount of tracer administered (in $\mathrm{Bq}$ ) and the total body weight $(\mathrm{kg})$, enabling within- and between-subject semiquantitative comparisons.

Quantification of PET Data. The dynamic PET data from the pancreas and liver, expressed as the SUV, were fitted to a 1-tissuecompartment (1TC) model by use of the PMOD PKIN kinetic modeling module. Tracer kinetics in blood (determined from venous blood sampling) were used as the input function. The 1TC model (Fig. 1) assumes that the entire PET signal from a tissue originates from the blood volume perfusing the tissue and the total uptake of the radiotracer, both specifically and nonspecifically bound. Three parameters determine the goodness of fit between the model and the experimental data: the volume of distribution of blood in tissue $(\mathrm{vB}), K_{1}$ (extraction of tracer into tissue), and $k_{2}$ (washout of tracer from tissue). The compound parameter total volume of distribution (vT) is the ratio of $K_{1}$ to $k_{2}$.

GLP-1R occupancy was estimated by assuming that the baseline vT $(0.05 \mu \mathrm{g} / \mathrm{kg})$ represented zero occupancy. The vT after coinjection of increasing doses of DO3A-exendin- 4 and the vT at baseline were used to calculate the apparent GLP-1R occupancy (as a percentage) caused by DO3A-exendin- 4 according to the following equation:

$$
\text { Occupancy }(\%)=100-\frac{\mathrm{vT}(\mu \mathrm{g} / \mathrm{kg})}{\mathrm{vT}_{\text {baseline }}} \times 100
$$

\section{Statistical Analysis}

A parametric, 2-tailed, unpaired Student $t$ test or a 1-way ANOVA was performed with GraphPad Prism version 5.04 (GraphPad); $P<$ 0.05 was considered significant.

\section{RESULTS}

\section{Small-Animal Studies}

Distribution in Rodent Organs. Uptake in the pancreas (determined by ex vivo measurement of tissues in the well counter) at $60 \mathrm{~min}$ after administration was decreased from the baseline $(0.1$ $\mu \mathrm{g} / \mathrm{kg})$ by $42 \%(P=0.0214), 74 \%(P=0.0075)$, and $90 \%(P=$ 0.0033 ) by coadministration of DO3A-exendin-4 at 1,2 , and 100 $\mu \mathrm{g} / \mathrm{kg}$, respectively (Fig. 2). At $80 \mathrm{~min}$, the respective decreases were $31 \%(P=0.0284), 46 \%(P=0.04)$, and $82 \%(P<0.0001)$. No statistical differences between the groups were found at $30 \mathrm{~min}$ (the $P$ value for the difference between the baseline and coinjection of $100 \mu \mathrm{g} / \mathrm{kg}$ was 0.13 ), but the trend was similar to those at 60 and $80 \mathrm{~min}$. A dose of $100 \mu \mathrm{g} / \mathrm{kg}$ is expected to occupy the majority of accessible GLP-1R because it is 100 times higher than the previously reported in vivo $\mathrm{ED}_{50}$. The absolute tissue uptake was relatively constant over time at all levels of blocking, likely because of rapid tissue extraction in combination with slow washout or irreversible trapping.

Next, we wanted to investigate the effect of reducing the amount of functional GLP-1R within the pancreas. This experiment was done by selectively inducing the destruction of $\beta$-cells in the islets

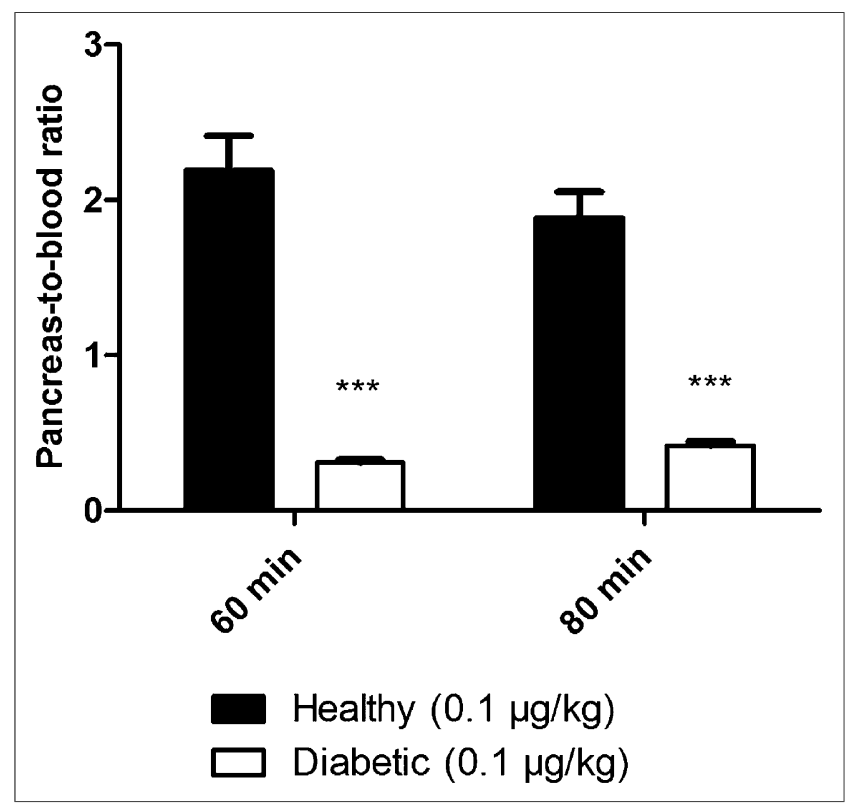

FIGURE 3. Destruction of viable $\beta$-cells by streptozotocin decreased in vivo uptake in pancreas by more than $80 \%$ at 60 and 80 min after intravenous administration of ${ }^{68} \mathrm{Ga}-\mathrm{DO} 3 \mathrm{~A}$-exendin-4, as measured by ex vivo organ distribution. Decrease was similar to that seen after complete GLP-1R inhibition by unlabeled peptide (Fig. 2). Asterisks indicate significance compared with results in healthy subjects, as assessed by Student $t$ test. ${ }^{\star \star *} P<0.001$. 


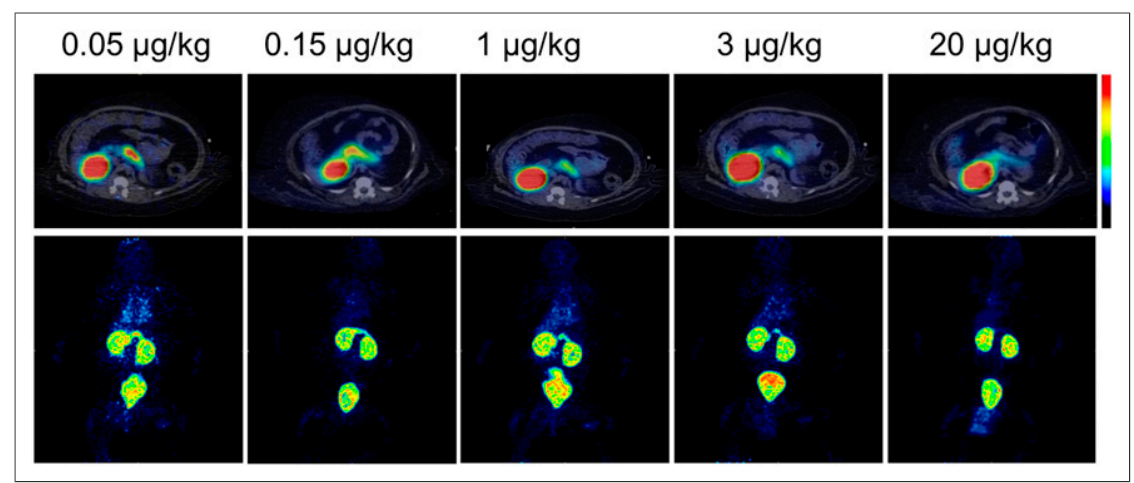

FIGURE 4. Representative PET/CT images of cynomolgus monkeys after coinjection of ${ }^{68} \mathrm{Ga}-\mathrm{DO} 3 \mathrm{~A}-$-exendin-4 and various amounts of unlabeled DO3A-exendin-4. Increasing concentration of unlabeled peptide to more than expected $\mathrm{ED}_{50}(>0.25 \mu \mathrm{g} / \mathrm{kg})$ resulted in competition for GLP-1R between tracer and unlabeled peptide. This effect was seen in pancreas only. High pancreatic uptake seen at tracer levels was almost completely abolished by coadministration of unlabeled peptide at $20 \mu \mathrm{g} / \mathrm{kg}$. Transaxial images (top row) are summations of dynamic sequences 30-90 min after tracer administration, normalized to SUV of 7 . Whole-body maximum-intensity projections (bottom row) were acquired 90-120 min after tracer administration.

of Langerhans, which express GLP-1R to a higher degree than non-insulin-producing cells. Uptake in animals with streptozotocin-induced diabetes (blood glucose concentrations of $>20 \mathrm{mM}$ in sequential measurements), again determined by ex vivo organ distribution measurements, was decreased by more than $80 \%(P<$ 0.001) compared with the baseline in healthy controls (blood glucose concentration of $6.7 \pm 1.3 \mathrm{mM}$ ) after both 60 and $80 \mathrm{~min}$ (Fig. 3).

Small-Animal PET Imaging of Rodents. The tracer was rapidly excreted to the kidneys (primarily the cortex but also the medulla), reaching an SUV of 10 in less than 5 min (data not shown). Gradual accumulation continued throughout the 60-min study.

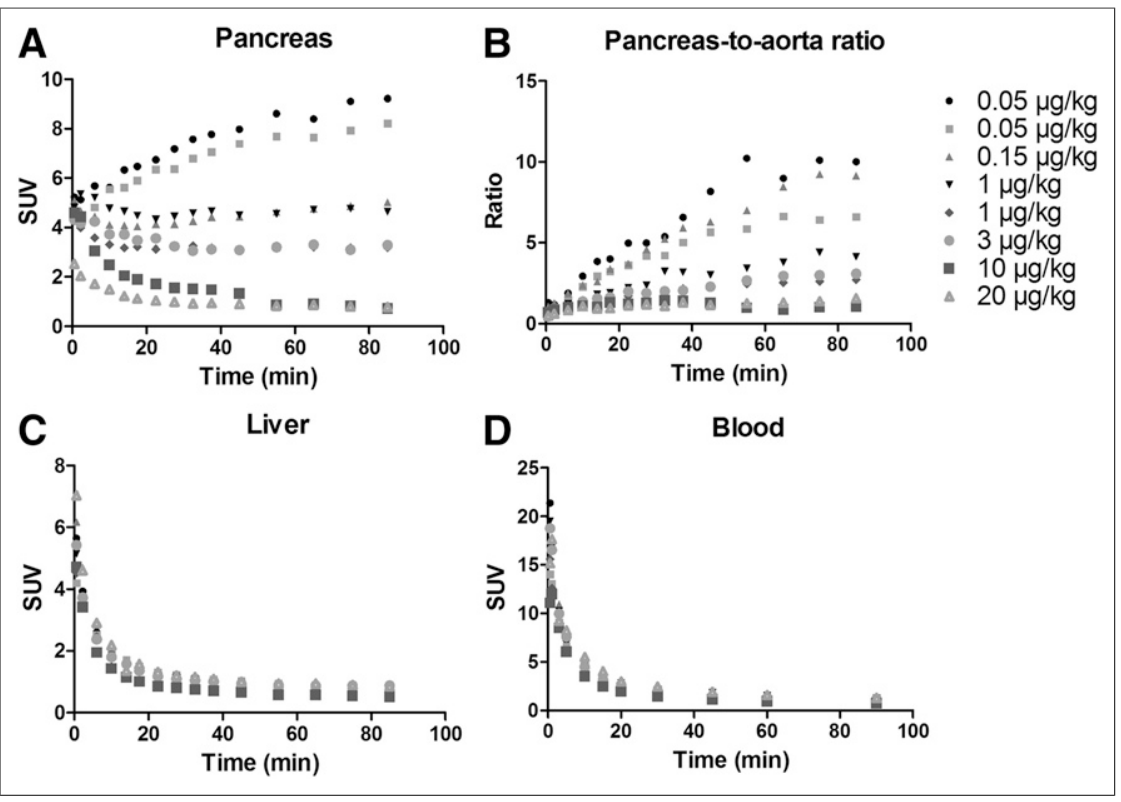

FIGURE 5. Time-activity curves describing uptake in pancreas $(A)$, pancreas-to-aorta ratio (B), uptake in liver (C), and uptake in blood (D) over time. Absolute uptake in GLP-1Rpositive pancreas was decreased by coadministration of increasing amounts of unlabeled DO3A-exendin- 4 , and modulated kinetics from gradual increase $(0.05 \mu \mathrm{g} / \mathrm{kg})$, "steady state" $(1-3 \mu \mathrm{g} / \mathrm{kg})$ to washout $(10-20 \mu \mathrm{g} / \mathrm{kg})$. Modulation of neither absolute uptake nor kinetics was seen in blood or GLP-1R-negative tissues, such as liver.
Given that the accumulation in the kidney cortex dominated the images throughout the study, proper delineation of the pancreas and other abdominal tissues was deemed difficult or impossible because of the potential errors imposed by partial-volume effects and spillover from the kidneys. In comparison, uptake in the kidneys, as determined by measurement of organ distribution, was more than 100 times greater than uptake in the liver or pancreas after 30-80 min.

\section{GLP-1R Imaging of \\ Nonhuman Primates}

PET/CT Scanning. The pancreas was readily visualized after the administration of ${ }^{68} \mathrm{Ga}$-DO3A-exendin- 4 under baseline conditions (administered mass dose, 0.05 $\mu \mathrm{g} / \mathrm{kg}$ ) (Figs. 4 and 5A). The tracer was excreted in the urine and trapped in the kidney cortex (Fig. 4, bottom row). No other tissues exhibited accumulation similar to that in the pancreas and kidneys. Minor uptake was detected in the intestine, liver, spleen, heart, and lungs. No uptake was seen in the brain, indicating the inability of the tracer to pass the blood-brain barrier. Measurements of blood and plasma samples taken during the 90-min scanning period suggested that radioactivity was present in plasma throughout the examination (data not shown).

Coinjection of increasing doses of unlabeled DO3A-exendin-4 decreased the uptake in the pancreas from peak SUVs of 8.2-9.2 at $90 \mathrm{~min}$ after the baseline $(0.05 \mu \mathrm{g} / \mathrm{kg})$ to SUVs of $5.0(0.15$ $\mu \mathrm{g} / \mathrm{kg}), 3.2-4.6(1 \mu \mathrm{g} / \mathrm{kg}), 3.3(3 \mu \mathrm{g} / \mathrm{kg}), 0.7(10 \mu \mathrm{g} / \mathrm{kg})$, and $0.8(20 \mu \mathrm{g} / \mathrm{kg})$ (Fig. 5A). The highest pharmacologic dose, $20 \mu \mathrm{g} / \mathrm{kg}$, designed to induce a large fraction of available GLP-1R, decreased pancreatic uptake by more than $90 \%$. The same decrease in absolute uptake as a result of escalated dose competition was seen for the pancreas-toaorta ratios (Fig. 5B). Uptake in GLP$1 \mathrm{R}$-negative tissues such as the kidneys and liver (Fig. 5C) or blood (Fig. 5D) was not influenced by the coadministration of unlabeled DO3A-exendin-4.

These results strongly indicated that uptake in the pancreas was mediated specifically by GLP-1R, as it could be dose dependently inhibited by progressive competition with DO3A-exendin-4. In contrast, tracer accumulation in GLP-1R-negative tissues such as the liver consisted solely of nonspecific uptake.

Quantification of PET Data. Uptake kinetics in the pancreas and liver were fitted to a 1TC model to quantify the biologic uptake and the washout process, which govern the tracer distribution over time.

The rate constant $K_{1}$, which determines total tissue uptake (free, specific, and nonspecific) from plasma decreased in the 
TABLE 1

Best-Fit Parameters for Pancreas and Liver with 1TC Model

\begin{tabular}{|c|c|c|c|c|c|c|c|c|c|c|}
\hline \multirow[b]{2}{*}{ Dose $(\mu g / k g)$} & \multicolumn{5}{|c|}{ Pancreas } & \multicolumn{5}{|c|}{ Liver } \\
\hline & vB & $K_{1}$ & $k_{2}$ & $\mathrm{vT}$ & $\begin{array}{c}\text { Residual sum } \\
\text { of squares }\end{array}$ & vB & $K_{1}$ & $k_{2}$ & vT & $\begin{array}{c}\text { Residual sum } \\
\text { of squares }\end{array}$ \\
\hline 0.05 & 0.21 & 0.07 & 0.01 & 8.39 & 10.86 & 0.25 & 0.04 & 0.19 & 0.2 & 2.28 \\
\hline 0.05 & 0.25 & 0.06 & 0.01 & 8.3 & 4.96 & 0.32 & 0.01 & 0.02 & 0.53 & 3.6 \\
\hline 0.15 & 0.27 & 0.04 & 0.01 & 4.24 & 12.48 & 0.34 & 0.01 & 0.04 & 0.18 & 1.29 \\
\hline 1 & 0.3 & 0.06 & 0.02 & 2.88 & 8.55 & 0.25 & 0.02 & 0.13 & 0.19 & 3.9 \\
\hline 1 & 0.35 & 0.03 & 0.01 & 3.2 & 8.72 & 0.32 & 0.01 & 0.02 & 0.3 & 0.55 \\
\hline 3 & 0.31 & 0.05 & 0.02 & 2.44 & 25.74 & 0.29 & 0.01 & 0.02 & 0.38 & 1.06 \\
\hline 10 & 0.45 & 0.02 & 0.03 & 0.77 & 15.41 & 0.37 & 0 & 0.01 & 0.3 & 4.72 \\
\hline 20 & 0.15 & 0.01 & 0.03 & 0.29 & 1.81 & 0.39 & 0 & 0.01 & 0.2 & 15.15 \\
\hline
\end{tabular}

pancreas as increasing doses of competing DO3A-exendin-4 were coinjected (Table 1). This finding can be interpreted as representing smaller amounts of available, nonoccupied GLP-1R. The rate constant $k_{2}$, which should not be influenced by escalating doses of DO3A-exendin-4, was relatively constant, increasing only slightly with the coinjection of DO3A-exendin-4 at $20 \mu \mathrm{g} / \mathrm{kg}$.

The compound parameter (vT), reflecting the total volume of distribution of the tracer in the pancreas, decreased dose dependently with increasing amounts of coinjected DO3A-exendin-4. In contrast, vT in the liver was not affected by coinjection of DO3A-exendin-4, confirming that the majority of tracer uptake did not involve GLP-1R binding.

GLP-1R occupancy in the pancreas and liver, estimated from changes in vT relative to the baseline, was plotted against the coinjected dose of DO3A-exendin-4 (Fig. 6). In the pancreas, nearly $100 \%$ occupancy was measured when DO3A-exendin-4 was coinjected at $20 \mu \mathrm{g} / \mathrm{kg}$. A receptor occupancy of $50 \%$ occurred at $0.15 \mu \mathrm{g} / \mathrm{kg}$, in the same range as the previously reported $\operatorname{ED}_{50}(0.25 \mu \mathrm{g} / \mathrm{kg})$ for exendin-4. As predicted, receptor occupancy in the GLP-1R-negative liver was negligible.

\section{DISCUSSION}

GLP-1R has been shown to be an attractive target for the imaging of focal clusters of $\beta$-cells, such as insulinomas and transplanted islets. The next steps in the imaging of $\beta$-cells are visualization and quantification of the islets diffusely distributed in the native pancreas. Progress in this area has been more difficult because of the lower density of $\beta$-cells in the target tissue (pancreas) than in the islet graft. Only preliminary data on the in

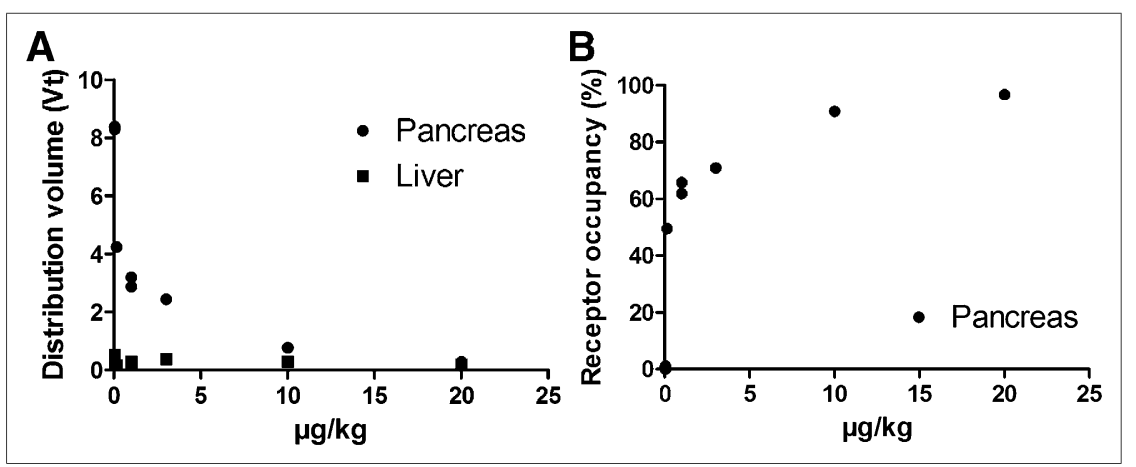

FIGURE 6. Kinetic modeling of cynomolgus data. Dose-dependent decrease in distribution volume because of dose escalation of unlabeled DO3A-exendin-4 was seen in pancreas but not in liver (A). In vivo GLP-1R occupancy at different doses of DO3A-exendin-4 in pancreas, as determined from parameters from 1TC model $(B)$. vivo quantification of native pancreatic $\beta$-cells have been reported with ${ }^{111} \mathrm{In}(12)$ or ${ }^{64} \mathrm{Cu}(8)$. A recent study describing the ${ }^{18} \mathrm{~F}$ labeling of exendin ${ }^{9-39}$ failed to show any GLP-1R-specific tracer binding in the pancreas (13). For quantitative imaging of the cell mass (such as $\beta$-cells), rather than receptors, with a ligand such as exendin- 4 , it is imperative for the expression of the target protein to be stable both over time and between cells of the same type. The expression of GLP-1R in $\beta$-cells is influenced by extracellular factors such as glucose levels. Thus, additional studies are required to clarify whether quantitative measurements of $\beta$-cell mass, with GLP-1R as a proxy, can be achieved with exendin-4 PET.

In the present study, we described a methodology of not only visualizing but also quantifying GLP-1R in the pancreas through the use of the PET nuclide ${ }^{68} \mathrm{Ga}$, which offers several advantages. First, the use of a positron-emitting nuclide is imperative, as no other noninvasive imaging technique has the same potential for the quantification of biologic processes as PET. Second, ${ }^{68} \mathrm{Ga}$ has a short half-life (68 min), which yields significantly lower total and focal radiation doses than ${ }^{111} \mathrm{In}$ and ${ }^{64} \mathrm{Cu}$. The radiation dose is not important in oncologic applications but is a limiting factor in longitudinal studies of healthy volunteers or subjects with type 1 or type 2 diabetes.

The third and most important improvement made possible through the use of ${ }^{68} \mathrm{Ga}$ is the high specific radioactivity of the tracer. Specific radioactivity is defined as the concentration of a radioactive material in a sample; in macromolecular tracers, it is expressed as radioactivity per macromolecule amount $(\mathrm{Bq} / \mathrm{mol})$. High specific radioactivity becomes increasingly important when the imaging agent used has a high affinity for its target. The dose of exendin-4 required for a physiologic response in rodents, nonhuman primates, and humans is about $0.5 \mu \mathrm{g} / \mathrm{kg}$. In previous studies that failed to detect the specific binding of exendinbased radiopharmaceuticals in the pancreas, much higher doses were administered; therefore, we posit that in those studies, GLP-1R in the pancreas was inadvertently saturated through the administration of doses of unlabeled ligand that were too high, thus providing a false-negative response.

In the present study, we failed to detect significant GLP-1R-specific tracer interactions after the coinjection of unlabeled DO3A-exendin-4 doses exceeding $1 \mu \mathrm{g} / \mathrm{kg}$. This result was attributable to partial ( 3 and $10 \mu \mathrm{g} / \mathrm{kg})$ or full $(20 \mu \mathrm{g} / \mathrm{kg})$ saturation. However, when we reduced the peptide 
dose to less than $1 \mu \mathrm{g} / \mathrm{kg}$, we obtained a high level of pancreatic uptake of ${ }^{68} \mathrm{Ga}$-DO3A-exendin-4. This result was made possible by the high specific activity $(>100 \mathrm{MBq} / \mathrm{nmol})$, which yielded a strong radioactive signal despite the low dose of administered ligand. A dose of $0.05 \mu \mathrm{g} / \mathrm{kg}$ is the lowest dose of DO3A-exendin-4 peptide that is possible with current technologies, and we consider this the baseline.

It is important that PET imaging of pancreatic GLP-1R was not possible in rats; the results that we obtained for rodent models were based on ex vivo organ distribution measurements. The failure to visualize the rodent pancreas despite the GLP-1R-specific uptake was related to the proximity $(<1 \mathrm{~cm})$ to a high level of accumulation in the kidneys because of excretion. Barring a method of significantly reducing renal excretion, we conclude that the in vivo imaging of rodent pancreatic islets with ${ }^{68} \mathrm{Ga}-\mathrm{DO} 3 \mathrm{~A}-$-exendin-4 is difficult or impossible. Larger animal models, such as nonhuman primates or pigs, should be explored instead.

Tracer retention in the kidney cortex was high in cynomolgus monkeys as well. However, maximum-intensity projections (Fig. 4, bottom row) gave a false impression of excessive spillover into pancreatic tissue. On regular PET/CT images (Fig. 4, top row), the problem was less severe. The entire pancreas could be clearly delineated on CT images, and the spillover or partial-volume effects for the kidneys were not an issue, except perhaps for the distal end of the head of the pancreas. In humans, in whom the pancreas is closer to the left kidney (right on transaxial PET images), there could be spillover into the pancreatic tail instead. However, the greater distance between the organs in humans may alleviate this potential problem.

A drawback of using a small nonhuman primate model, such as a cynomolgus monkey, for kinetic modeling of PET data is the inability to obtain arterial blood samples. Therefore, we instead used venous blood samples as the input function for the 1TC model. The venous blood curve is normally delayed in comparison with the arterial blood curve, especially during the initial biodistribution phase. It is conceivable that a reference tissue model could have been used to avoid the lack of arterial blood samples and metabolite analysis. However, because no suitable reference tissue is present in the abdominal region, we opted for venous input.

GLP-1R-specific ${ }^{68}$ Ga-DO3A-exendin-4 uptake was seen only in the pancreas in the present study. Hepatic uptake (Fig. 6) and muscular uptake are not displaceable and thus consist almost solely of nonspecific tracer accumulation. These are sites of clinical importance for islet transplantation, and the low level of background uptake suggests that the quantification of GLP-1R in transplanted islet grafts may be possible for these tissues (4).

GLP-1R is also expressed in lung nodules and cells in the intestines. The reason that such tissues are difficult to visualize by PET with ${ }^{68} \mathrm{Ga}-\mathrm{DO} 3 \mathrm{~A}$-exendin-4 or other radiopharmaceuticals is likely a phenomenon called the partial-volume effect (14). It has further been suggested that the imaging or quantification of $\beta$-cells in the pancreas with GLP-1R or other PET markers is precluded by the partial-volume effect with current technology (15). It is true that this phenomenon prevents the accurate visualization and quantification of individual cells, including $\beta$-cells, by PET. However, we are interested in measuring the integrated radioactive signal from the tracer associated with all $\beta$-cells in the pancreas. This measurement is possible as long as the pancreas is larger than the spatial resolution of the PET system. This scenario is analogous to quantifying dopamine receptors in the striatum in vivo with ${ }^{11} \mathrm{C}$-raclopride: the entire tissue PET volume of interest does not consist of postsynaptic tissue with a high receptor density. The majority of the volume of interest rather consists of connective tissue, axons, and blood vessels. Nevertheless, the integrated average receptor density across the entire striatum can be readily quantified despite the inability to visualize or quantify individual postsynaptic regions or receptors.

\section{CONCLUSION}

The results presented in this study show that ${ }^{68} \mathrm{Ga}-\mathrm{DO} 3 \mathrm{~A}-\mathrm{exen}-$ din-4 uptake in the pancreas is mediated by receptor-specific mechanisms in rodents and nonhuman primates and decreased by the selective destruction of $\beta$-cells. These results suggest that GLP-1R can be quantified noninvasively in vivo in nonhuman primates, and this suggestion has major implications for the prospect of clinical imaging of native and transplanted $\beta$-cells.

\section{DISCLOSURE}

The costs of publication of this article were defrayed in part by the payment of page charges. Therefore, and solely to indicate this fact, this article is hereby marked "advertisement" in accordance with 18 USC section 1734. This study was supported by grants from the Swedish Medical Research Council (65X-12219-15-6), Barndiabetesfonden, and Tore Nilsson's Foundation for Medical Research. Olle Korsgren's position is supported by the National Institutes of Health (2U01AI065192-06), Olof Eriksson's position is supported by EXODIAB (Excellence of Diabetes Research in Sweden), and Ram K. Selvaraju's position is supported by VINNOVA. No other potential conflict of interest relevant to this article was reported.

\section{REFERENCES}

1. Eriksson O, Alavi A. Imaging the islet graft by positron emission tomography. Eur J Nucl Med Mol Imaging. 2012;39:533-542.

2. Wu Z, Kandeel F. Radionuclide probes for molecular imaging of pancreatic betacells. Adv Drug Deliv Rev. 2010;62:1125-1138.

3. Tornehave D, Kristensen P, Romer J, Knudsen LB, Heller RS. Expression of the GLP-1 receptor in mouse, rat, and human pancreas. J Histochem Cytochem. 2008;56:841-851.

4. Körner M, Stockli M, Waser B, Reubi JC. GLP-1 receptor expression in human tumors and human normal tissues: potential for in vivo targeting. $J$ Nucl Med. 2007;48:736-743.

5. Wild D, Macke H, Christ E, Gloor B, Reubi JC. Glucagon-like peptide 1-receptor scans to localize occult insulinomas. N Engl J Med. 2008;359:766-768.

6. Wild D, Béhé M, Wicki A, et al. [Lys40(Ahx-DTPA- ${ }^{111}$ In) $\mathrm{NH}_{2}$ ] exendin-4, a very promising ligand for glucagon-like peptide-1 (GLP-1) receptor targeting. J Nucl Med. 2006;47:2025-2033.

7. $\mathrm{Wu} \mathrm{Z}$, Todorov $\mathrm{I}, \mathrm{Li} \mathrm{L}$, et al. In vivo imaging of transplanted islets with ${ }^{64} \mathrm{Cu}$ DO3A-VS-Cys40-exendin-4 by targeting GLP-1 receptor. Bioconjug Chem. 2011;22:1587-1594.

8. Connolly BM, Vanko A, McQuade P, et al. Ex vivo imaging of pancreatic beta cells using a radiolabeled GLP-1 receptor agonist. Mol Imaging Biol. 2012;14:79-87.

9. Pattou F, Kerr-Conte J, Wild D. GLP-1-receptor scanning for imaging of human beta cells transplanted in muscle. N Engl J Med. 2010;363:1289-1290.

10. Brom M, Oyen WJ, Joosten L, Gotthardt M, Boerman OC. ${ }^{68}$ Ga-labelled exendin-3, a new agent for the detection of insulinomas with PET. Eur J Nucl Med Mol Imaging. 2010;37:1345-1355.

11. Young AA, Gedulin BR, Bhavsar S, et al. Glucose-lowering and insulin-sensitizing actions of exendin-4: studies in obese diabetic $(o b / o b, d b / d b)$ mice, diabetic fatty Zucker rats, and diabetic rhesus monkeys (Macaca mulatta). Diabetes. 1999;48:1026-1034.

12. Brom M, Baumeister P, Melis M, et al. Determination of the beta-cell mass by SPECT imaging with In-111-DTPA-exendin-3 in rats. J Nucl Med. 2009;50(suppl. 2):39P.

13. Wang Y, Lim K, Normandin M, Zhao X, Cline GW, Ding YS. Synthesis and evaluation of $\left[{ }^{18} \mathrm{~F}\right]$ exendin $(9-39)$ as a potential biomarker to measure pancreatic $\beta$-cell mass. Nucl Med Biol. 2012;39:167-176.

14. Hickeson M, Yun M, Matthies A, et al. Use of a corrected standardized uptake value based on the lesion size on CT permits accurate characterization of lung nodules on FDG-PET. Eur J Nucl Med Mol Imaging. 2002;29:1639-1647.

15. Kwee TC, Basu S, Saboury B, Torigian DA, Naji A, Alavi A. Beta-cell imaging: opportunities and limitations. J Nucl Med. 2011;52:493. 